\title{
Low Level Donor Chimerism of CDI9 CAR-T Cells Returned to Complete Donor Chimerism in Patients with Relapse After Allo-Hematopoietic Stem Cell Transplant
}

This article was published in the following Dove Press journal: OncoTargets and Therapy

\author{
Qing $\mathrm{Li}^{1}$ \\ Juan Mu (D) \\ Jijun Yuan ${ }^{2}$ \\ Zhenxing Yang ${ }^{2}$ \\ Jia Wang $\mathbb{D}^{\prime}$ \\ Qi Deng' \\ 'Department of Hematology, Tianjin First \\ Central Hospital, Tianjin 300192, People's \\ Republic of China; ${ }^{2}$ Medical Department, \\ Shanghai Genbase Biotechnology Co., \\ Ltd, Shanghai 20I203, People's Republic \\ of China
}

Correspondence: Qi Deng

Email kachydeng@I26.com
Purpose: To investigate the donor chimerism changes and curative effects associated with the use of autologous anti-CD19 chimeric antigen receptor (CAR) T cells with B-cell acute lymphoblastic leukemia (B-ALL) presenting with a low donor chimerism level and relapse after allogeneic hematopoietic stem cell transplant (allo-HSCT).

Methods: Nine patients with B-ALL showing low donor chimerism level and relapse after alloHSCT were enrolled. Patients 1-3 received CD19 CAR-T cell therapy using cells derived from autologous peripheral blood mononuclear cells (PBMCs) (comprising a mixture of patient and original donor cells) as their donors could not provide PBMCs. Samples from the other six patients (Patients A-F) were investigated only in vitro. The changes in the degree of donor chimerism, function of the CD19 CAR-T cells and T cells in all nine patients were analyzed in vitro. The therapeutic effects and adverse events (AEs) were also evaluated in Patients 1-3.

Results: The CAR-T cells and T cells in all nine patients showed complete donor chimerism restoration following a 12-day culture period in vitro. These CD19 CAR-T cells demonstrated strong cytotoxicity towards Nalm 6 cells in vitro except in patients 3 and D. In the latter patients, the absolute numbers of all subsets, especially the CD8 + T-cell absolute numbers in peripheral blood were very low. Patients 3 and D showed relatively short durations from transplant to recurrence and received chemotherapy after relapse. In the patients receiving CD19 CAR-T cell therapy, the most commonly observed AE was grade 1 to 2 cytokine release syndrome. None of the cases showed acute graft-versus-host disease during treatment. Patients 1 and 2 achieved complete response with complete restoration of donor chimerism. Patient 3 , who received the same CD19 CAR-T cell therapy, did not respond to this therapy.

Conclusion: CD19 CAR-T cells derived from patients relapsed after allo-HSCT with a low level of donor chimerism were effective for salvage therapy and could restore to complete donor chimerism after 12 days' culture in vitro.

Trial Registration: Humanized CD19 CAR-T cell therapy for relapse or refractory B-cell lymphoma or acute B lymphocytic leukemia, ChiCTR1800019622, Registered 24 November 2018, http://www.chictr.org.cn/index.aspx.

Keywords: chimeric antigen receptor, acute lymphoblastic leukemia, allogeneic hematopoietic stem cell transplant, relapse, donor chimerism

\section{Introduction}

Allogeneic hematopoietic stem cell transplant (allo-HSCT) is an effective treatment strategy for B-cell acute lymphoblastic leukemia (ALL). The provision of therapy 
to patients with relapsed B-ALL after allo-HSCT remains a major challenge as their median survival duration is shorter than 6 months. ${ }^{1}$ Salvage therapy for cases with B-ALL relapse after allo-HSCT includes chemotherapy, second transplant, and donor lymphocyte infusion (DLI). However, these therapies may cause serious toxicity or graft-versus-host disease - a potentially lethal immune response. ${ }^{2,3}$ Anti-CD19 chimeric antigen receptor-modified (anti-CD19 CAR) T cell therapy has a high response rate and affords long-term remission in patients with relapsed/refractory B-ALL. ${ }^{4,5}$ Several studies showed that donor-derived allogeneic CD19 CAR-T cell therapy could effectively eradicate B-cell malignancies in patients with relapsed B-ALL after allo-HSCT. ${ }^{6-8}$ Moreover, allogeneic CD19 CAR-T cell therapy could achieve notable results without the occurrence of significant graft-versus-host disease. ${ }^{8,9}$ Nevertheless, some donors, especially unrelated donors, are unable to provide the peripheral blood mononuclear cells (PBMCs) necessary for CD19 CAR-T cell therapy. However, when the degree of donor chimerism is very low and the tumor load is high, it is not clear whether patients could achieve complete response (CR) through the use of CD19 CAR$\mathrm{T}$ cells derived from their own PBMCs. We therefore aimed to evaluate the curative effects associated with the introduction of CD19 CAR-T cells derived from patient's own PBMCs in three individuals exhibiting low levels of donor chimerism and relapse after allo-HSCT. We also aimed to evaluate the changes in donor chimerism, T-cell subsets, and killing activities of all CAR-T cells in the blood specimens obtained from all nine enrolled patients in vitro.

\section{Materials and Methods}

\section{Patients and Clinical Trial Design}

Nine patients with B-ALL who relapsed after allo-HSCT and exhibited a low level of donor chimerism $(<25 \%)$ between November 2018 and July 2019 were enrolled in our study. Of these, three (patients 1 to 3 ) were enrolled in a clinical trial at the Department of Hematology in Tianjin First Central Hospital (Tianjin, China) and received CD19 CAR-T cell expressing humanized anti-CD19 scFv and 41BB-CD3 $\zeta$ costimulatory-activation domain therapy (ChiCTR1800019622). All three patients provided informed consent prior to enrolment. The other six patients (Patients A to F) provided informed consent to participate in our experimental research. The low level of donor chimerism of all nine patients was due to relapse after alloHSCT. The final follow-up visit for endpoint analysis was conducted on January 31, 2020. This study was approved by the Medical Ethics Committee of the Department of Hematology, Tianjin First Central Hospital (Tianjin, China). (Ethics Committee Approval No. 2018N105KY).

\section{Source of T Cells for CDI9 CAR-T Cell Therapy and in vitro Experiments}

The donors for patients 1 to 3 were unable to provide PBMCs for CD19 CAR-T cell therapy owing to the presence of infectious disease or other reasons. Thus, autologous PBMCs obtained from the three patients themselves were administered as sources of $\mathrm{T}$ cells for the CD19 CAR-T cell therapy. The CD19 CAR-T cells of the other six patients (patients A to F), derived from their own PBMCs as well, were collected for in vitro evaluation only.

\section{Generation of CDI9 CAR-T Cells}

We collected $50 \mathrm{~mL}$ leukocyte collection from the nine relapsed patients with B-ALL by leukapheresis, then PBMCs were isolated by Ficoll density gradient centrifugation. CD3 $+\mathrm{T}$ cells $\left(1 \times 10^{6}\right)$ were selected using CD3 microbeads (MiltenyiBiotec, Inc., Cambridge, MA, USA), stimulated with anti-CD3/anti-CD28 mAb-coated Human T-Expander beads (the ratio of this bead to $\mathrm{CD} 3+\mathrm{T}$ cell was 1:1) (Cat. No. 11141D; Thermo Fisher Scientific, Inc., Waltham, MA, USA), and cultured in T-cell medium XVivo 15 (Lonza Group, Ltd., Basel, Switzerland) supplemented with $250 \mathrm{IU} / \mathrm{mL}$ interleukin-2 (IL-2; Proleukin; Novartis International AG, Basel, Switzerland). Then, the T-cell medium X-Vivo 15 supplemented with $250 \mathrm{IU} / \mathrm{mL}$ interleukin-2 was added every two days or depending on the CD19 CAR-T cell growth. After $48 \mathrm{~h}$ of cell culture, at which point the CD19+ leukemic cells could not be detected in the culture by flow cytometry (FCM) (BD Biosciences, San Jose, CA, USA), T cells $\left(3 \times 10^{6}\right)$ were transduced with a lentiviral vector encoding CD19-CAR constructs $\quad(10 \mu \mathrm{g} ; \quad$ lenti-CD19-2rd-CAR; Shanghai Genbase Biotechnology Co., Ltd., Shanghai, China) and cultured in medium containing recombinant human IL-2 $(250 \mathrm{U} / \mathrm{mL})$. In addition, the $\mathrm{CD} 3+\mathrm{T}$ cells from the PBMCs of the nine patients were cultured in T-cell medium X-Vivo 15 supplemented with $250 \mathrm{IU} / \mathrm{mL}$ IL-2 as control group. 


\section{Transduction Efficiency, Immune Phenotype of T Lymphocytes and Cytotoxicity of All the CDI9 CAR-T Cells and T Cells}

After a 12-day culture, the transduction efficiencies of anti-CD19CAR were analyzed by FCM (BD Biosciences, San Jose, CA, USA). The expression levels of the programmed death 1 receptor (PD-1) (BD Biosciences) in the nine patients were detected by FCM. The T lymphocyte functions of patients 1-3 prior to culture and 28 days following CD19 CAR-T cell therapy were detected by FCM. The T lymphocyte phenotypes of patients A-F were detected prior to in vitro culture. The analysis included regulatory $\mathrm{T}$ cells, Th1, Th2, naive $\mathrm{T}$ cells, effector $\mathrm{T}$ cells, central memory $\mathrm{T}$ cells, and effector memory $\mathrm{T}$ cells among $\mathrm{CD} 3+\mathrm{CD} 4+\mathrm{CD} 8-\mathrm{T}$ cells, and naive $\mathrm{T}$ cells, effector $\mathrm{T}$ cells, central memory $\mathrm{T}$ cells, and effector memory $\mathrm{T}$ cells among $\mathrm{CD} 3+\mathrm{CD} 4-\mathrm{CD} 8+\mathrm{T}$ cells. We evaluated the percentage and absolute numbers of $\mathrm{T}$ cells in the various subsets.

The cytotoxicities of all the CD19 CAR-T cells and T cells towards CD19+ Nalm 6 cells (American Type Culture Collection, Manassas, VA, USA), which is characterized by low expression of PD-L1 (2.02\%), were evaluated.

\section{Experimental Method \\ FCM}

FCM analysis of PBMCs or T cells was performed using $2-5 \times 10^{6}$ total cells per condition. The dilution of antibodies was performed according to the operating instructions.

Cells were isolated and stained with anti-CD3-APC (Catalog number GMP-10,977-H001, MiltenyiBiotec, Inc.) and with anti-CD19-PE (1:20, Shanghai Genbase Biotechnology Co., Ltd., Shanghai, China) for $15 \mathrm{~min}$ at room temperature in a dark place to measure the transduction efficiencies of anti-CD19CAR in CD19 CAR-T cells. The CD19 CAR-T cell expression in CD3 $+\mathrm{T}$ cells of peripheral blood was observed by the same method.

The effect of CD19 CAR-T cells towards CD19+ Nalm 6 cells was analyzed using anti-CD3-APC and anti-CD19PC7 (Catalog number IM3628, Beckman Coulter, Inc.). The residual proportions of Nalm 6 cells were detected.

The expression of PD- 1 on CD3+ T lymphocytes was analyzed using anti-CD279-FITC (Catalog number $560795 \mathrm{Hu}, \mathrm{BD}$ Biosciences). The $\mathrm{T}$ lymphocyte phenotypes were analyzed using anti-CD4-FITC (Catalog number130-049-201, MiltenyiBiotec, Inc.)/CXCR3-PE /CD3-Percp/CCR10-APC/CCR6-PC7/CD8-APCCY7 (Catalog number 130-091-112, MiltenyiBiotec, Inc.)/ CCR4-BV421,/CCR7-PE/CD62L-APC/CD45RO-PC7

(Catalog number130-046-001, MiltenyiBiotec, Inc.)/ CD45RA-V500/CD127-PE (Catalog number: 130-102984, MiltenyiBiotec, Inc.)/CD25-APC (Catalog number: 130-099-393, Miltenyi Biotec, Inc.). T cell subsets were defined as follows: naïve T cells: CD45RA+CCR7+CD62L +; effector $\mathrm{T}$ cells: CD45RA+CCR7-CD62L-; regulatory T cells: $\mathrm{CD} 4+\mathrm{CD} 25+\mathrm{CD} 127$ low; central memory $\mathrm{T}$ cells: CCR7+CD45RA-CD62L+; effector memory $\mathrm{T}$ cells: CCR7-CD45RA-CD62L-; Th1: CXCR3+CCR4-CCR6CCR10-;Th2: CCR4+CCR6-CXCR3-CCR10-.

\section{qPCR for Anti-CDI9 CAR DNA Detection}

Genome of Peripheral Blood was extracted using Qiagen D Neasy Blood and Tissue Kit (Beijing Nobleryder Technology Co., LTD.). qPCR primer sequences were as follows: 7 e11-F: GATCTGGGACCGACTACACC; 7 e11R: CCCTTGCTGACAGAAATAGACA. The genomic DNA was diluted to $20 \mathrm{ng} / \mu \mathrm{L}$ and the reaction system was configured according to the Standard reaction system. The fluorescence group was selected as SYBR Green Master Mix (Applied Biosystems; Thermo Fisher Scientific, Inc.) and the quenching fluorescence group was NONE for detection. The reference fluorescence was ROX. qPCR was performed with a StepOne ${ }^{\mathrm{TM}}$ Real-Time PCR System machine (Applied Biosystems; Thermo Fisher Scientific, Inc.). Reaction conditions were as follows: $50^{\circ} \mathrm{C}$ for 2 $\min , 95^{\circ} \mathrm{C}$ for $2 \mathrm{~min}, 95^{\circ} \mathrm{C}$ for $15,60^{\circ} \mathrm{C}$ for $1 \mathrm{~min}, 40$ Cycles.

\section{qPCR for Donor Chimerism Analysis}

The degree of donor chimerism of all nine patients was investigated from the day of relapse to day 12 of cultivation. Genomic DNA was isolated from the peripheral blood samples or bone marrow with the Genmag DNA blood Kit on a Genmag automated DNA extractor (Changzhou, China). The concentration and purity of the DNA samples was determined by UV photometry. In all PCRs, 10ng DNA and MIX were amplified multiplexly per reaction. Then, $1 \mu \mathrm{L}$ PCR product, $9 \mu \mathrm{L}$ mix of deionized formamide and liz500 (length standard) were denatured at $95^{\circ} \mathrm{C}$ for 3 mins. Capillary electrophoresis was carried out on an ABI 3730 instrument. Dates were imported and analyzed by Genemapper. Chimerism analysis by short tandem repeats (STR)-PCR was performed 
by determining the peak area of pre-transplant host and donor STR alleles in sample of post-transplant.

\section{Cytotoxicity in vitro}

Each group of CD19 CAR-T cells $\left(1 \times 10^{5}\right)$ or T cells $(20 \times$ $\left.10^{5}\right)$ were co-cultured with Nalm 6 cells $\left(1 \times 10^{5}\right)$ for 48 h. The target and effector cells were cultured with $500 \mathrm{IU} /$ $\mathrm{mL}$ IL-2 in an incubator containing $5 \% \mathrm{CO}_{2}$ at $37^{\circ} \mathrm{C}$ for $48 \mathrm{~h}$ in 24-well plates. Cytotoxicities of CD19 CAR-T cells were detected using lactate dehydrogenase (LDH) cytotoxicity Assay Kit (Dojindo Molecular Technologies, Inc.) at $490 \mathrm{~nm}$, according to manufacturer's instructions. Then, cells of all the groups were seeded in 96-well plates (100 $\mu \mathrm{L} /$ well) at $37^{\circ} \mathrm{C}, 5 \% \mathrm{CO}_{2}$ for 30 mins. The absorbance was measured at $490 \mathrm{~nm}$. Cytotoxicity (\%) was calculated as (Sample absorbance-Sample control absorbance)/(Absorbance of cell maximum enzyme activityAbsorbance of sample control).

\section{CDI9 CAR-T Cell Therapy Process}

To improve the CAR-T cell therapy efficacy and reduce the tumor load, patients 1-3 received pretreatment with fludarabine $\left(30 \mathrm{mg} / \mathrm{m}^{2} /\right.$ day) and cytarabine $\left(1000 \mathrm{mg} / \mathrm{m}^{2} /\right.$ day) for 5 days from the day of autologous PBMC collection (Figure 1). On the day of CAR-T cell infusion (12 days following PBMCcollection), the proportions of leukemic cells and degree of donor chimerism in the bone marrow were observed. Then, the CD19 CAR-T cells derived from the autologous PBMCs of the three patients were infused $\left(1 \times 10^{6} \mathrm{cells} / \mathrm{kg}\right)$ on day $0 .{ }^{10,11}$

\section{Adverse Events and CDI9 CAR-T Cell Expansion}

With regard to side effects, cytokine release syndrome (CRS) was observed 0-28 days following CAR-T cell infusion. The CRS was graded according to the adopted CRS scoring system and the National Cancer Institute Common Terminology Criteria for AE v4.03 following CAR-T cell infusion. ${ }^{12}$ The secretion levels of cytokines including IL-6, IL-2R, tumor necrosis factor- $\alpha$ (TNF- $\alpha$ ), and IL- 8 were measured on days $0,7,14,21$, and 28 by enzyme-linked immunosorbent assay with a doubleantibody one-step sandwich method. The CD19 CAR-T cell expression in CD3 $+\mathrm{T}$ cells of peripheral blood was observed by FCM at $0,4,7,14,21,28,60,90$, and 120 days following CAR-T cell infusion (anti-CD19 antibody, Shanghai Genbase Biotechnology Co., Ltd). In patients 1 and 2, expression was detected approximately 120 days following CD19 CAR-T cell infusion. The DNA level of the anti-CD19-CAR gene by real-time qPCR analysis was also detected at $0,4,7,14,21,28,60,90$, and 120 days following CD19 CAR-T cell infusion.

\section{Therapeutic Effect Observation}

At 14, 28, 60, 90, and 120 days following CD19 CAR-T cell infusion, the proportions of leukemic cells in the bone marrow were observed in the two patients (patients 1 and 2) who achieved CR. The changes in the degree of donor chimerism in the bone marrow were concurrently analyzed. Patient 3, who did not achieve CR, died after 55 days of CD19 CAR-T cell therapy.

\section{Statistics}

All data are expressed as the means \pm standard deviations (SD). Statistical analyses were performed using SPSS18.0 software. Differences between repeated experiments of the two groups were investigated using the unpaired $t$-test and $F$-test. For all statistical tests, values of $P<0.05$ were considered statistically significant.

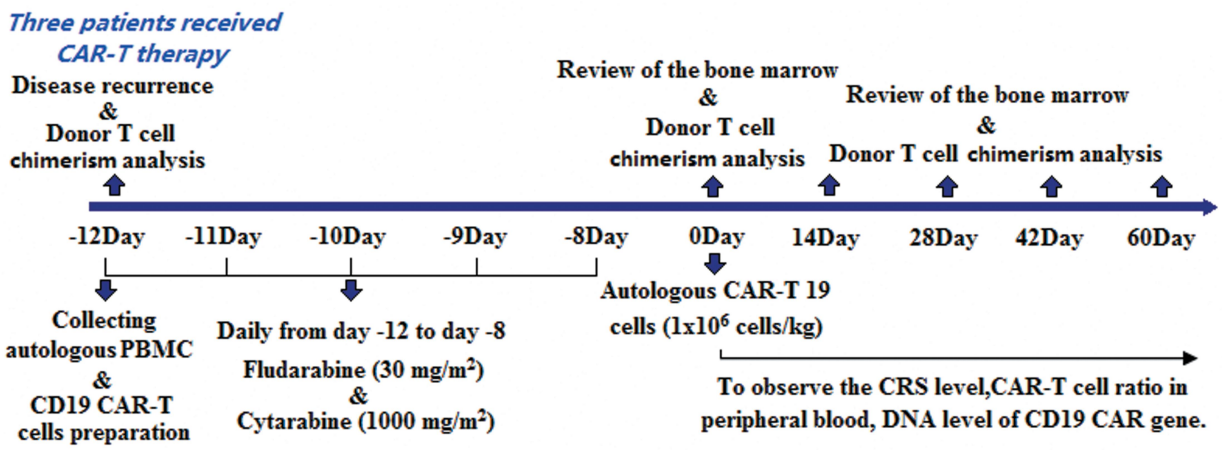

Figure I Treatment procedure and observation of efficacy and side effects in the three patients receiving CAR-T cell therapy. Abbreviations: CRS, cytokine release syndrome; CAR, chimeric antigen receptor. 


\section{Results}

\section{Characteristics of All the Patients in Our Study}

All the participants enrolled in our study constituted patients with B-ALL who showed relapse after alloHSCT. Three (patients 1-3) underwent preclinical evaluations and received CD19 CAR-T cell therapy. The other six (Patients A-F) underwent preclinical evaluations only. Patients 3 and D had a relatively short duration from transplant to recurrence. On reviewing their medical history, we found that only these two patients received chemotherapy following recurrence. The detailed characteristics of all patients are summarised in Table 1.

\section{Transduction Efficiency, Donor Chimerism Changes, Cytotoxicity of CAR-T Cells and T Cells, and Immune Phenotype of the \\ T Lymphocytes in All Patients}

Following 12-day culture, the mean transduction efficiency of anti-CD19CAR for all nine patients was 47.11 $\pm 8.47 \%$. During cell culture in vitro, the percentage of leukemic B-cells decreased to zero while donor CAR-T cells and $T$ cells increased gradually (Table 2). Meanwhile, the mean transduction efficiency of the three patients who received CD19 CAR-T cell therapy (patients 1-3) was $44.26 \pm 6.05 \%$. When the cells were harvested, the CD19 CAR-T cell numbers of patients $1-3$ was $12.45 \times 10^{6}, 7.11$ $\times 10^{6}$ and $0.91 \times 10^{6}$ cells $/ \mathrm{kg}$, respectively. Patients $1-3$ received a dose of $1.12 \times 10^{6}, 1.05 \times 10^{6}$ and $0.91 \times$ $10^{6} \mathrm{cells} / \mathrm{kg}$ humanized CD19 CAR-T cell infusion, respectively, on day 0 .

The mean donor chimerism degree in the peripheral blood of patients $1-3$ was $12.67 \pm 2.96 \%$ when they relapsed after allo-HSCT. In comparison, the mean donor chimerism degree in Patients A-F was $15.56 \pm 6.61 \%$. CAR-T cells or $\mathrm{T}$ cells cultured in vitro were derived from own-PBMCs of all nine patients and selected using CD3 microbeads. Few leukemic B cells were identified in the in vitro culture system following CD3 microbead selection. The CAR-T cells of patients 1-3 were restored to complete donor chimerism $(99.64 \%, 99.23 \%$, and $98.86 \%$ ) by 12 -day culture in vitro, as were the CAR-T cells of patients A-F. We further observed that the T cells of all nine patients also achieved complete donor chimerism restoration upon culture in vitro (Figure $2 \mathrm{~A}$ and $\mathrm{B}$ ).

The expression of PD-1 receptors in the CD3+ T cells of the nine patients at relapse after allo-HSCT was detected by FCM (Figure 2C). The PD-1 expression levels in patients 3 and $\mathrm{D}$ exceeded $60 \%$ (67.9\% and $63.1 \%$, respectively), whereas those in the other seven patients were below $50 \%$. We performed preclinical evaluations of the $\mathrm{T}$ cells and CD19 CAR-T cells from all nine patients in vitro.

The residual proportions of Nalm 6 cells were detected using FCM methods after $48 \mathrm{~h}$ of co-culture with CD19 CAR-T cells of all the nine patients at an E:T ratio of 1:1

Table I Patient Baseline and Therapy-Related Characteristics

\begin{tabular}{|c|c|c|c|c|c|c|c|c|}
\hline Patient & Age & Sex & Malignancy & Donor Type 2 & $\begin{array}{l}\text { GVHD Before } \\
\text { Recurrence }\end{array}$ & $\begin{array}{l}\text { Time from } \\
\text { Transplant to } \\
\text { Recurrence } \\
\text { (Months) }\end{array}$ & $\begin{array}{l}\text { Chemo- } \\
\text { Therapy } \\
\text { After } \\
\text { Recurrence }\end{array}$ & $\begin{array}{l}\text { Time to Stop } \\
\text { Immuno- } \\
\text { Suppressive Therapy } \\
\text { (Months) }\end{array}$ \\
\hline 1 & 48 & $M$ & B- ALL & MSDT & Grade II cGVHD & 18 & No & 7 \\
\hline 2 & 42 & $\mathrm{~F}$ & B-ALL $(\mathrm{Ph}+)$ & MMUDT $(8 / 10)$ & Grade I cGVHD & 58 & No & 51 \\
\hline 3 & 16 & $\mathrm{~F}$ & B-ALL & MUDT & Grade II aGVHD & 4 & $\begin{array}{l}\text { Two courses } \\
\text { (VDCPx2) }\end{array}$ & 4 \\
\hline A & 46 & $F$ & B-ALL & MMSDT $(5 / 10)$ & Grade I aGVHD & 14 & No & 6 \\
\hline B & 18 & $M$ & B-ALL (Ph+) & Haplo-HSCT & Grade I cGVHD & 13 & No & 7 \\
\hline C & 24 & $M$ & $\begin{array}{l}\text { B-ALL } \\
(\text { TCF3-PBXI) }\end{array}$ & Haplo-HSCT & Grade I aGVHD & 10 & No & 5 \\
\hline D & 39 & $\mathrm{~F}$ & B-ALL & MSDT & No & 3 & $\begin{array}{l}\text { One course } \\
\text { (VCP) }\end{array}$ & 3 \\
\hline$E$ & 15 & $\mathrm{~F}$ & B-ALL $(\mathrm{Ph}+)$ & MMUDT $(9 / 10)$ & Grade III aGVHD & 36 & No & 24 \\
\hline $\mathrm{F}$ & 37 & $\mathrm{~F}$ & B-ALL & Haplo-HSCT & Grade I cGVHD & 12 & No & 6 \\
\hline
\end{tabular}

Notes: Pt I-3: The three patients receiving CAR-T therapy; Pt A-F: The six patients evaluated in vitro only.

Abbreviations: HSCT, hematopoietic stem cell transplant; cGVHD, chronic graft-versus-host disease; aGVDH, acute graft-versus-host disease; B-ALL, B-cell acute lymphoblastic leukemia; HLA, human leukocyte antigen; MDST, HLA-matched sibling donor transplant; MMSDT, HLA-mismatched sibling donor transplant; MUDT, HLAmatched unrelated donor transplant; MMUDT, HLA-mismatched unrelated donor transplant; haplo-HSCT, haploid HSCT. 
Table 2 The Percentage of Leukemic B-Cell and Donor Cells in vitro Culture System of CAR-T Cells and T Cells

\begin{tabular}{|c|c|c|c|c|c|c|c|c|c|c|c|c|}
\hline & \multicolumn{4}{|c|}{ Date of Relapse } & \multicolumn{4}{|c|}{ Cultivation Day 7} & \multicolumn{4}{|c|}{ Cultivation Day I 2} \\
\hline & $\begin{array}{l}\% \text { of } \\
\text { AL } \\
\text { Cells } \\
\text { in } \\
\text { CAR-T }\end{array}$ & $\begin{array}{l}\% \text { of } \\
\text { AL } \\
\text { Cells } \\
\text { in } \\
\text { T-Cells }\end{array}$ & $\begin{array}{l}\% \text { of } \\
\text { Donor } \\
\text { Cells in } \\
\text { CAR-T } \\
\text { Cells }\end{array}$ & $\begin{array}{l}\% \text { of } \\
\text { Donor } \\
\text { Cells } \\
\text { in } \\
\text { T Cells }\end{array}$ & $\begin{array}{l}\% \text { of } \\
\text { AL } \\
\text { Cells } \\
\text { in } \\
\text { CAR-T }\end{array}$ & $\begin{array}{l}\% \text { of } \\
\text { AL } \\
\text { Cells } \\
\text { in } \\
\text { T-Cells }\end{array}$ & $\begin{array}{l}\% \text { of } \\
\text { Donor } \\
\text { Cells in } \\
\text { CAR-T } \\
\text { Cells }\end{array}$ & $\begin{array}{l}\% \text { of } \\
\text { Donor } \\
\text { Cells } \\
\text { in } \\
\text { T Cells }\end{array}$ & $\begin{array}{l}\% \text { of } \\
\text { AL } \\
\text { Cells } \\
\text { in } \\
\text { CAR-T }\end{array}$ & $\begin{array}{l}\% \text { of } \\
\mathrm{AL} \\
\text { Cells } \\
\text { in } \\
\text { T-Cells }\end{array}$ & $\begin{array}{l}\% \text { of } \\
\text { Donor } \\
\text { Cells in } \\
\text { CAR-T } \\
\text { cells }\end{array}$ & $\begin{array}{l}\% \text { of } \\
\text { Donor } \\
\text { Cells } \\
\text { in } \\
\text { T Cells }\end{array}$ \\
\hline Pt I & 1.36 & 1.38 & 11.22 & 11.22 & 0.00 & 0.00 & 84.78 & 56.23 & 0.00 & 0.00 & 99.64 & 99.13 \\
\hline Pt 2 & 2.06 & 1.89 & 16.08 & 16.08 & 0.00 & 0.00 & 80.34 & 49.68 & 0.00 & 0.00 & 99.23 & 99.56 \\
\hline Pt 3 & 1.03 & 1.22 & 10.72 & 10.72 & 0.00 & 0.00 & 65.02 & 42.05 & 0.00 & 0.00 & 98.86 & 99.49 \\
\hline $\mathrm{Pt} A$ & 1.11 & 1.09 & 20.55 & 20.55 & 0.00 & 0.00 & 84.65 & 55.23 & 0.00 & 0.00 & 98.98 & 99.28 \\
\hline Pt B & 0.92 & 0.66 & 8.82 & 8.82 & 0.00 & 0.00 & 81.26 & 49.58 & 0.00 & 0.00 & 99.15 & 99.05 \\
\hline Pt C & 1.63 & 2.04 & 23.12 & 23.12 & 0.00 & 0.00 & 80.29 & 60.15 & 0.00 & 0.00 & 98.96 & 99.39 \\
\hline Pt D & 2.15 & 1.99 & 18.67 & 18.67 & 0.00 & 0.00 & 76.88 & 52.69 & 0.00 & 0.00 & 98.78 & 99.37 \\
\hline Pt E & 2.64 & 3.12 & 6.55 & 6.55 & 0.00 & 0.00 & 72.61 & 46.01 & 0.00 & 0.00 & 99.64 & 99.89 \\
\hline $\mathrm{Pt} F$ & 0.99 & 0.87 & 15.63 & 15.63 & 0.00 & 0.00 & 69.04 & 44.25 & 0.00 & 0.00 & 98.64 & 99.22 \\
\hline
\end{tabular}

Notes: Pt I-3: The three patients receiving CAR-T therapy. CAR-T cells were derived from patient' sown PBMCs. Pt A-F: The six patients evaluated in vitro only. CAR-T cells were derived from patient's own PBMCs. D: Donor chimerism analysis. The CAR-T cells and T cells on the day of relapse were selected using CD3 microbeads. The percentage of donor cells was obtained by $\mathrm{QPCR}$ as described in the Materials and Methods section.

(Figure 3A). 36.08\% of CD19+ Nalm 6 cells remained in patient 3 and $24.06 \%$ in patient D. However, residual CD19+ Nalm 6 cells were below $10.0 \%$ in the other seven specimens. Similarly, strong cytotoxicity towards CD19+ Nalm 6 cells at an E:T ratio of 1:1 at 0,24 , and $48 \mathrm{~h}$ was observed using an $\mathrm{LDH}$ cytotoxicity test kit, although the cytotoxicity of patient 3 was lower than that of patients 1 and 2 at $48 \mathrm{~h}$ (Figure $3 \mathrm{~B}$ ) and the cytotoxicity of patient D was lower than that of patients A, B, C, E, and $\mathrm{F}$ (Figure 3C). The T cells demonstrated a certain extent of cytotoxicity towards CD19+ Nalm 6 cells at an E:T ratio of 20:1 at $48 \mathrm{~h}$. The cytotoxicity levels of the $\mathrm{T}$ cells towards Nalm 6 cells in patient 3 were lower than those in patients 1 and 2 . In addition, the cytotoxicity levels in patient $\mathrm{D}$ were lower than those in the other five patients in this group (Figure 3D).

We also evaluated the percentage and absolute numbers of T cells in the various subsets among the nine patients. The $\mathrm{CD} 3+\mathrm{CD} 8+\mathrm{CD} 4-$ and $\mathrm{CD} 3+\mathrm{CD} 4+\mathrm{CD} 8-\mathrm{T}$ cell expression in peripheral blood was detected using FCM methods (Figure 4A). In patient 3, who showed CD19 CAR-T cell therapy failure, the percentage of effector memory $\mathrm{T}$ cells in the CD3+CD4-CD8+ T cells was $100 \%$ prior to therapy. This value declined to $2.39 \%$ following therapy (Figure 4B). However, in this patient, the absolute numbers of all the subsets were lower than those of the other two patients with CD19 CAR-T cell therapy success (patients 1 and 2). Particularly, the CD8 + T cell absolute numbers were very low in patient 3 (Figure $4 \mathrm{C}$ ). In patients $\mathrm{A}-\mathrm{F}$, the cytotoxicity levels of the T cells and CD19 CAR-T cells in patient $\mathrm{D}$ were lower than those in the other five patients. We observed similar changes (Figure 4D and E) as in patients $1-3$. The absolute numbers of all the subsets in patient $\mathrm{D}$ were lower than those of the other five patients, whose CAR-T cells or $\mathrm{T}$ cells demonstrated strong cytotoxicity towards Nalm6 cells. Particularly, the CD8 + T cell absolute numbers were very low in patient $\mathrm{D}$.

\section{Adverse Events Associated with CDI9 CAR-T Cell Therapy}

The CD19 CAR-T cell therapy was well tolerated in all patients. Notable AEs included grade 1 to $2 \mathrm{CRS}$. Other AEs included high fever with chills, headache, dizziness, muscle ache, anorexia, edema, oliguria, liver dysfunction, and renal insufficiency. The patients were provided antipyretic drugs and methylprednisolone for AE treatment. AEs related to the CD19 CAR-T cell therapy were relieved after 12 days of infusion. None of the patients showed acute GVHD (aGVHD) during CD19 CAR-T cell therapy.

In the CD19 CAR-T cell therapy group, we measured the levels of cytokines. In patients 1 and 2, the highest serum levels of IL-6 were 286.2 and $159.7 \mathrm{U} / \mathrm{mL}$, respectively, on day 7 following infusion. In addition, the levels of IL-2R, IL-8, IL-10, TNF- $\alpha$, and ferritin also reached their peak on day 7 after infusion. The highest serum level of IL- 6 in patient 3 was $35.1 \mathrm{U} / \mathrm{mL}$ on day 4 following infusion. The levels of the other cytokines in patient 3 


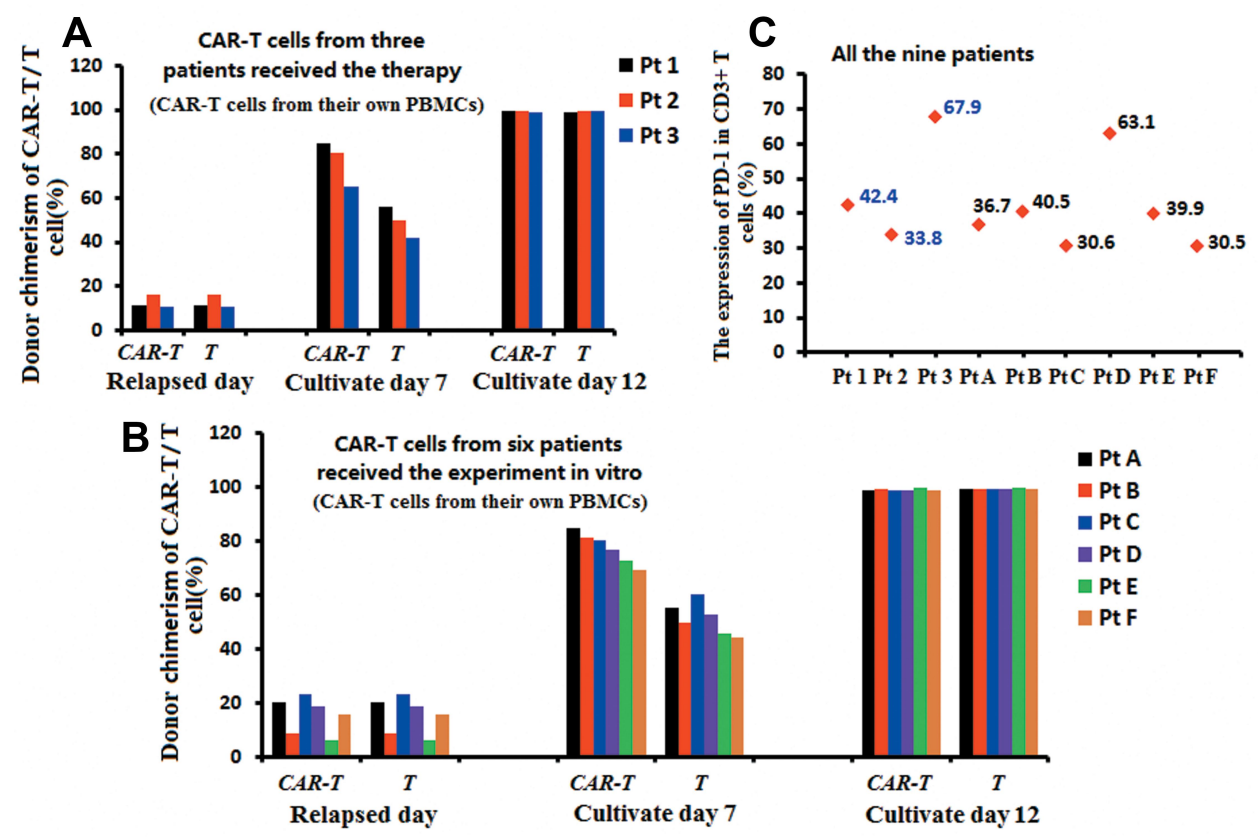

Figure 2 Donor chimerism changes and expression of PD-I on T cells in all nine patients. Donor chimerism was detected using CD3+ cell specimens from the patients' own PBMCs. (A) Donor chimerism of CAR-T cells and T cells cultured on days 0.7 and I2. CAR-T cells and T cells were all from the three patients who received CDI9 CAR-T cell therapy. Following 12 days' in vitro culture, the mean donor chimerism degree of the CAR-T cells and T cells was restored to $99.24 \pm 0.39 \%$ (patients I-3). (B) Donor chimerism of CAR-T cells and T cells from the six patients was evaluated only in vitro (patients A-F). Following 12 days' in vitro culture, the mean donor chimerism degree was restored to $99.03 \pm 0.35 \%$. (C) The PD-I expression level in CD3+ T cells from all nine patients. Patients 3 and D exceeded $60 \%$, whereas levels in the other seven patients were below $50 \%$ upon relapse. Chimerism was analyzed by qPCR as described in the Materials and Methods.

Abbreviations: PD-I, programmed death I receptor; B-ALL, B-cell acute lymphoblastic leukemia; CAR, chimeric antigen receptor.

changed irregularly throughout the treatment process (Figure 5).

\section{Expansion of the CDI9 CAR-T Cells After Infusion}

The peak proportions of CD19 CAR-T cells in peripheral blood were $54.08 \%$ and $70.88 \%$ in patients 1 and 2 , respectively, on day 14 following infusion, and $20.4 \%$ in patient 3 on day 7 after infusion. The proportion of CD19 CAR-T cells declined slowly in patients 1 and 2 until 60 days following therapy, but dropped rapidly in patient 3 (Figure 6A). The DNA level of the antiCD19CAR gene showed the same tendency as that of the proportion of CD19 CAR-T cells assessed by cytometry (Figure 6B).

\section{Therapeutic Effects of CDI9 CAR-T Cells Early After Infusion}

As the dosage of lymphodepleting chemotherapy was relatively high, patients were in a state of bone marrow suppression when they received the infusion of CD19 CAR-T cells. The proportions of leukemic cells in the bone marrow of patients $1-3$ declined to $4.6 \%, 18.5 \%$, and $20.4 \%$, respectively, on the day of CAR-T cell infusion, their donor chimerism degree simultaneously increased to $40.28 \%, 31.02 \%$, and $25.5 \%$ in the bone marrow. Patients 1 and 2 achieved CR with incomplete count recovery on day 14 , and $\mathrm{CR}$ on day 28 following the infusion of CD19 CAR-T cells. They achieved complete donor chimerism restoration at this stage. Patient 3 did not respond to CD19 CAR-T cell therapy. He had progressive disease and subsequently received palliative treatment (Figure 6C and D).

\section{Maintenance Treatment Following CDI9 CAR-T Cell Therapy}

Patient 1 showed leukemia-free survival (LFS) with no aGVHD in the following 42 days. Then, in order to prevent recurrence of the disease following CR from CD19 CAR-T cell therapy, the patient received donor stem cell infusions twice (CD34+ cell proportions of $0.68 \times 10^{6}$ and $0.77 \times 10^{6}$ cells $/ \mathrm{kg}$ ) two and four months following CD19 CAR-T cell therapy. She exhibited grade I aGVHD during the two-time infusion and recovered promptly. In this patient, LFS was maintained with complete donor chimerism for 18 months. 

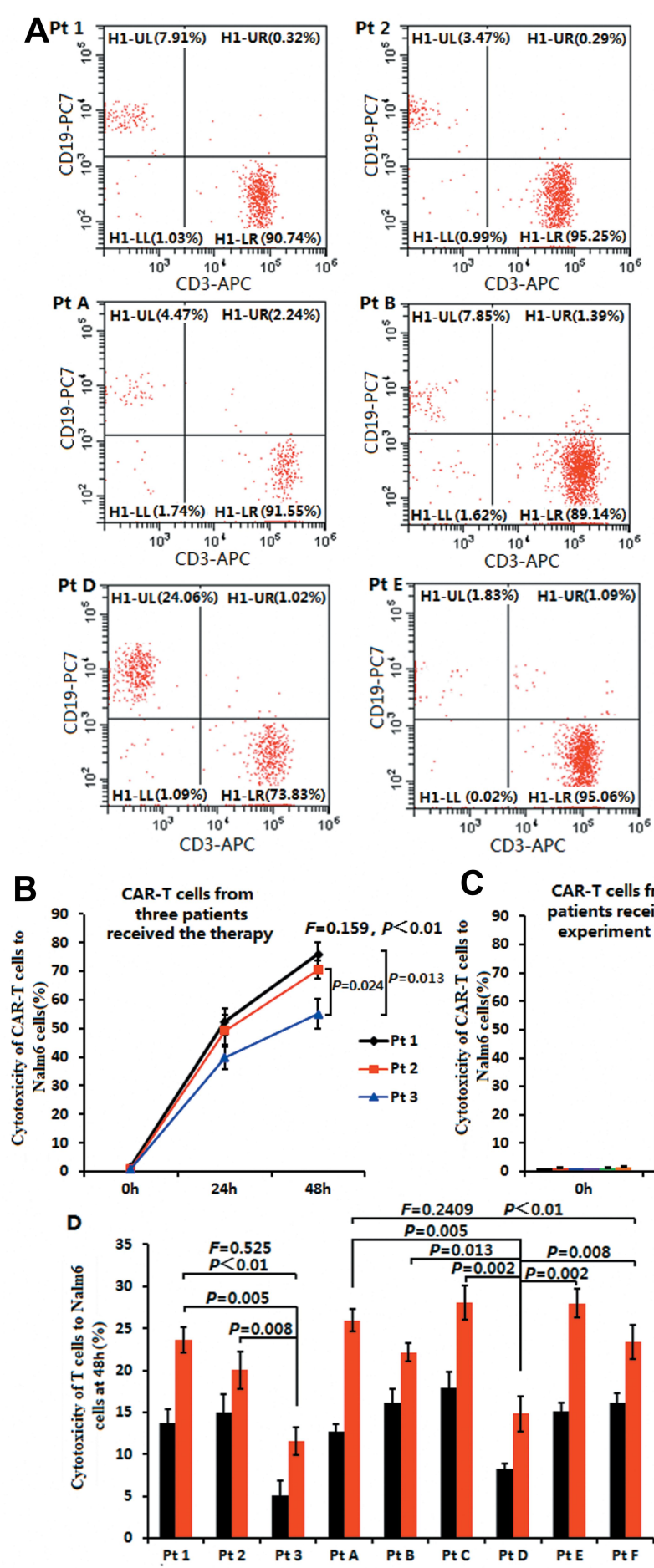
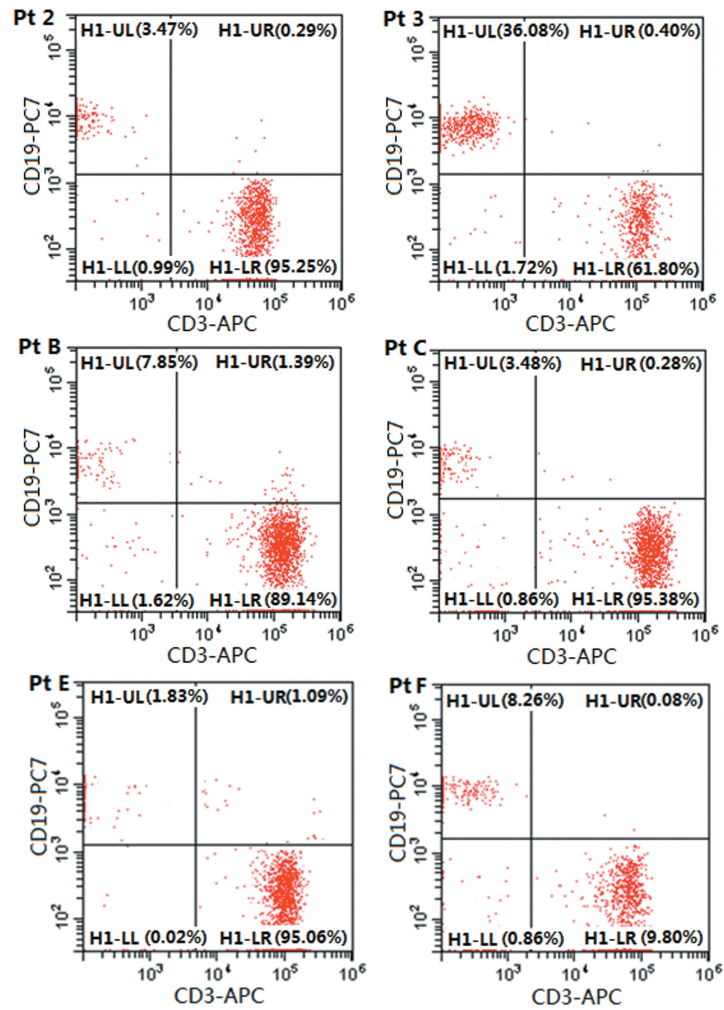

C $90 \begin{gathered}\text { CAR-T cells from six } \\ \text { patients received the } \\ \text { experiment in vitro }\end{gathered}$

$=0.982 P<0.05$

$P=0.007 \quad P=0.012$

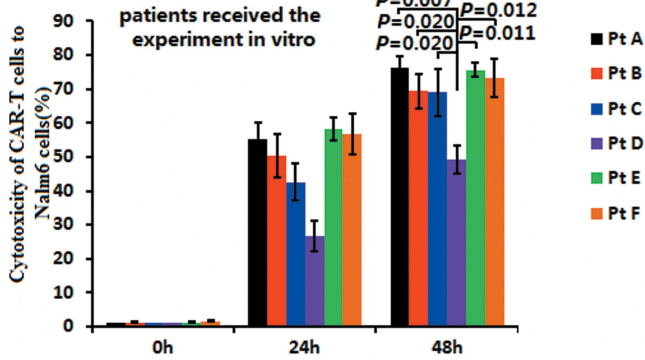

$24 \mathrm{~h}$

$48 \mathrm{~h}$

T cells from all the nine patients

- T cells before culture

a cells after culture

Figure 3 Cytotoxicity of T cells and CDI9 CAR-T cells toward Nalm6 cells. (A) Cytotoxicity of CAR-T cells towards CDI9+ Nalm 6 cells at an E:T ratio of I:I at 48h using FCM methods (B) The CAR-T cell cytotoxicity of patients I-3 at an E: Tratio of I:I at 0,24 , and $48 \mathrm{~h}$ using an LDH cytotoxicity test kit. (C) The CAR-T cell cytotoxicity of patients A-Fat an E:T ratio of I:I at 0, 24, and $48 \mathrm{~h}$ using an LDH cytotoxicity test kit. (D) T cell cytotoxicity in all patients at an E:T ratio of 20:I at $48 \mathrm{~h}$ using an LDH cytotoxicity test kit. The remaining CDI9+ Nalm 6 cells was $36.08 \%$ in patient 3 and $24.06 \%$ in patient $\mathrm{D}$ at $48 \mathrm{~h}$, whereas it was below $10.0 \%$ in the other seven specimens. The cytotoxicity of CAR-T cells and T cells towards Nalm 6 cells in patients 3 and D were lower than that of the other patients at $48 \mathrm{~h}$.

Abbreviation: CAR, chimeric antigen receptor.

Patient 2 received oral imatinib treatment and presented LFS with no aGVHD in the following 60 days. Then, he received donor stem cell infusion only once
(CD34+ cell proportion of $1.55 \times 10^{6}$ cells $/ \mathrm{kg}$ ) two months following CD19 CAR-T cell therapy. He presented grade II aGVHD and recovered promptly. In this patient, LFS 


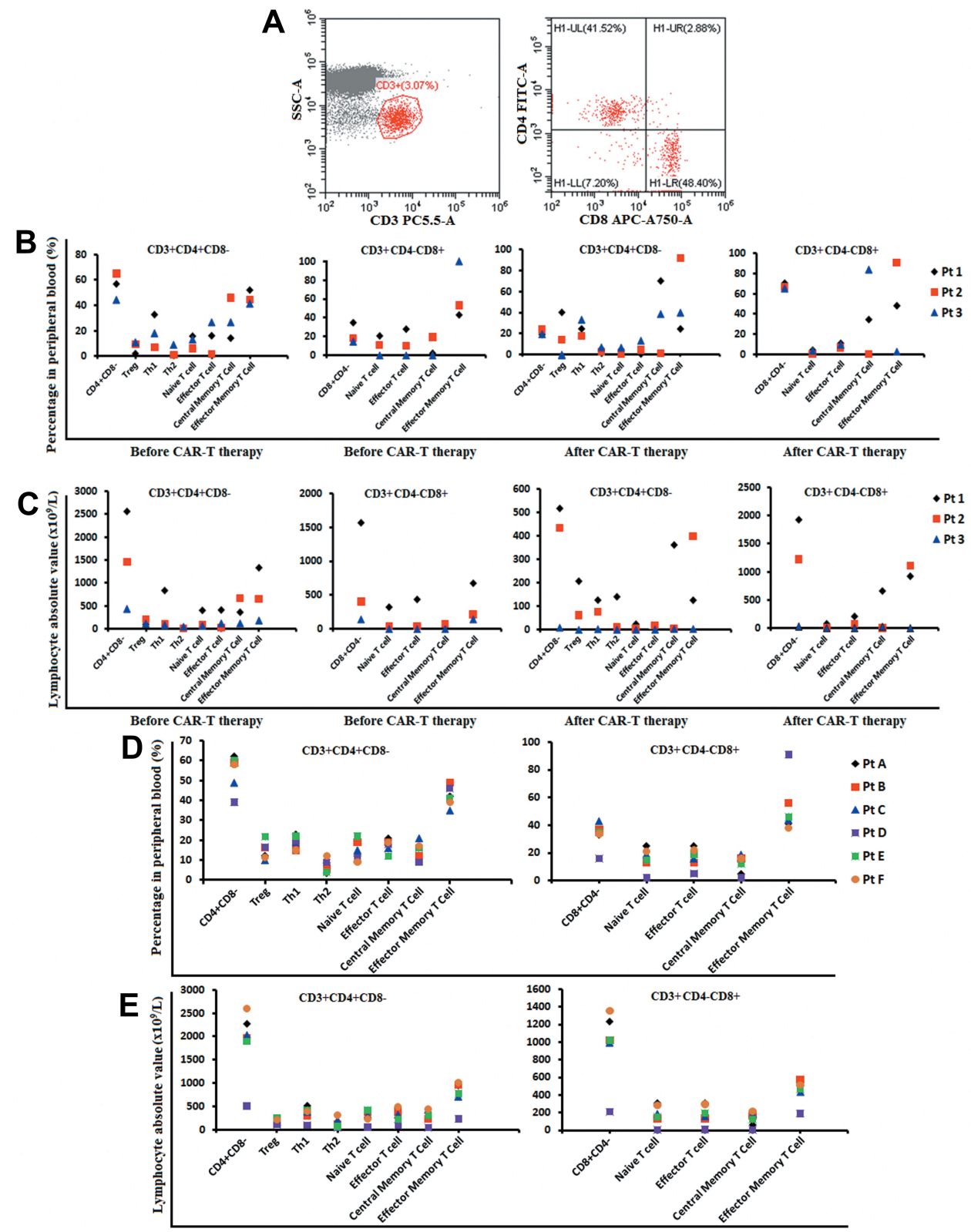

Figure 4 Immune phenotype of T lymphocytes of all patients using FCM methods. (A) CD3, CD8, and CD4 T cell expression in peripheral blood. (B and C) Percentage of effector memory T-cells and absolute numbers of all subsets before and after CAR-T therapy in patients I-3. (D and E) Percentage of effector memory T cells and absolute numbers of all subsets before and after CAR-T therapy in patients A-F. The absolute numbers of all subsets in patients 3 and $D$ were lower than those in other patients. Particularly, the CD8 + T-cell absolute numbers were very low.

Abbreviation: CAR, chimeric antigen receptor.

was maintained with complete donor chimerism for 17 months (Figure 6E).

Patient 3, who did not respond to CD19 CAR-T cell therapy, survived for two months after this clinical trial (Figure 6E).

\section{Discussion}

In this study, we found that the CD19 CAR-T cells derived from patients with B-ALL exhibiting low donor chimerism and disease recurrence following allo-HSCT could be restored to complete donor chimerism in vitro. AlloHSCT therapy has significantly improved the survival of patients with ALL in the past two decades. However, several patients with B-ALL remain at high risk of relapse after allo-HSCT and show poor long-term survival. 1,13,14 Guidelines for the management of post-transplantation relapse are limited. Alternative salvage treatments, such as second allo-HSCT, multi-agent chemotherapy, and 

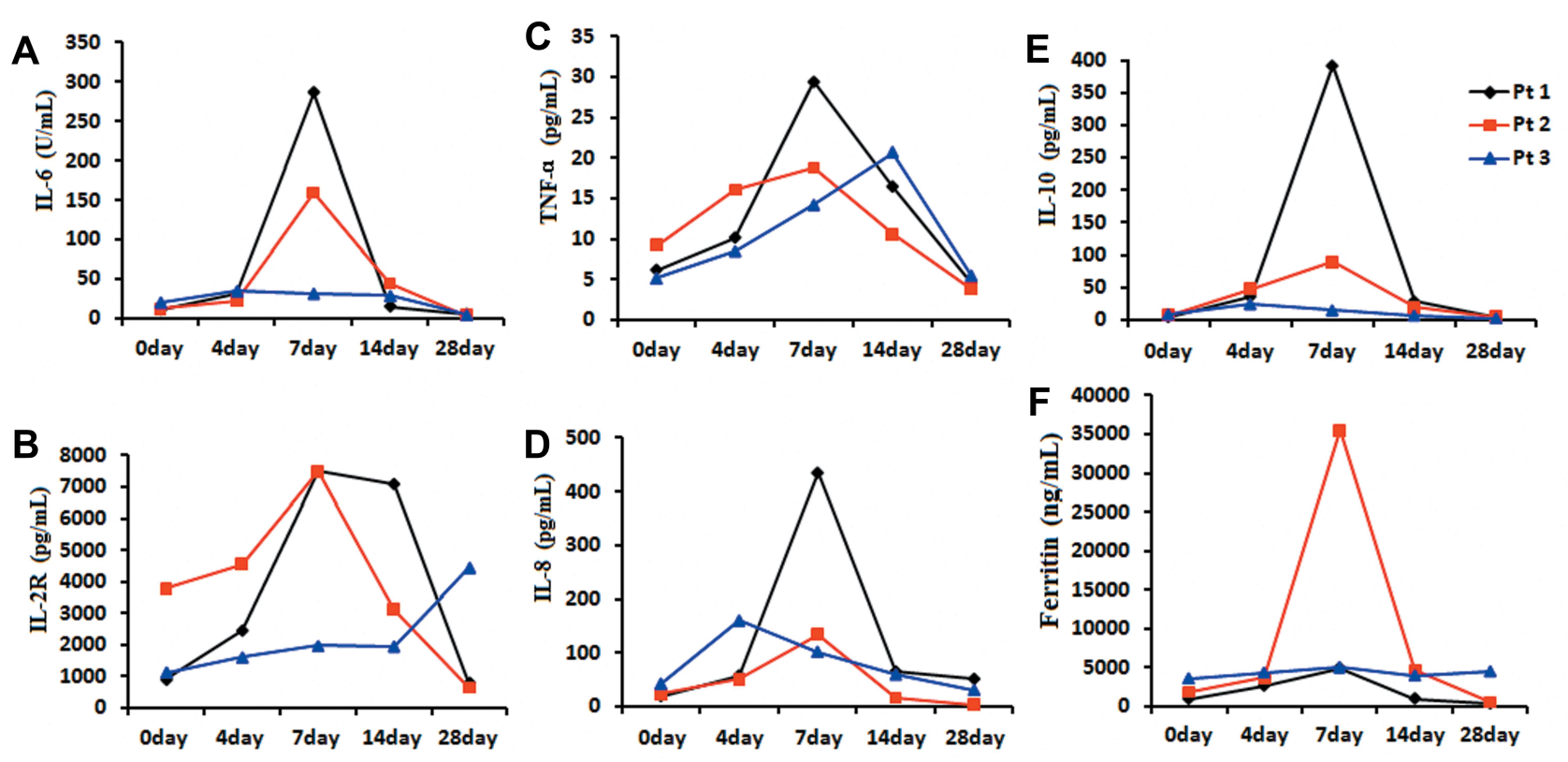

Figure 5 Changes in the serum cytokine levels during CAR-T cell therapy by enzyme-linked immunosorbent assay with a double-antibody one-step sandwich method in patients I-3.IL-6, IL-2R, IL-8, IL-10, TNF- $\alpha$, and ferritin (A-F) reached their peak on day 7 in patients I and 2 . The level of cytokines in patient 3 changed irregularly. Abbreviations: TNF, tumor necrosis factor; IL, interleukin; CAR, chimeric antigen receptor.

palliative care are associated with low rates of remission and poor long-term survival. ${ }^{15}$ Besides, DLI is a very effective salvage therapy for patients with ALL presenting relapse after allo-HSCT. However, aGVHD and chronic GVHD (cGVHD) may be caused by the infusion of a large number of donor T cells. ${ }^{16-18}$ The median survival period was only 6 months after DLI therapy in patients relapsed after allo-HSCT, because most patients exhibited no response to this therapy. ${ }^{3,19}$

CD19 CAR-T cell therapy has shown significant clinical efficacy in patients with relapsed/refractory B-ALL and a CR rate of $80-90 \% .^{20}$ Although some studies focused on donor-derived CD19 CAR-T cell therapy for patients with B-ALL exhibiting relapse after alloHSCT, ${ }^{6-8}$ the safety of this therapeutic strategy has not been confirmed. We estimated that the infusion of donor CD19 CAR-T cells may lead to the development of aGVHD in patients with relapse after allo-HSCT. However, no cases with serious aGVHD following CD19 CAR-T cell therapy have been reported in such settings. ${ }^{8}$ Therefore, the use of CD19 CAR-T cell therapy with its benefits of high efficiency and low toxicity can aid in overcoming the poor prognoses of patients with B-ALL showing relapse after allo-HSCT to a certain extent. ${ }^{21,22}$ Following allo-HSCT, the $\mathrm{T}$ cell function of patients is suppressed by monocytes. ${ }^{23}$ This may underlie in part the lower severity grade of CRS and GVHD observed in association with CD19 CAR-T cell therapy. In addition, patients' own $\mathrm{T}$ cells are in a state of long-term inhibition after allo-HSCT which may explain the donor chimerism recovery in in vitro culture. Moreover, the function of donor $\mathrm{T}$ cells is also inhibited to a certain extent by immunosuppressive therapy. The later the time of recurrence after allo-HSCT, the easier it is to achieve donor $\mathrm{T}$ cell functional restoration following immunosuppressive therapy. Therefore, the function of donor T cells recovers better in patients with long-term recurrence after alloHSCT, particularly in patients who did not receive immunosuppressive therapy at the time of disease recurrence.

In our study, patients 1 and 2 relapsed 18 and 58 months after allo-HSCT. By the time they relapsed, they had discontinued immunosuppressive therapy for about 7 and 51 months, respectively. However, patient 3 relapsed and discontinued immunosuppressive therapy 4 months after allo-HSCT and received two courses of chemotherapy. Patient $\mathrm{D}$ showed the same degree of disease progression as patient 3 . He had discontinued immunosuppressive therapy for about 3months and received one course of chemotherapy. Thus, we analyzed the cytotoxicity levels of the CAR-T cells and T cells in all nine patients. The cytotoxicity levels of the CAR-T cells and T cells towards Nalm 6 cells in patients 3 and D were lower than those in the other patients. The absolute numbers of all the subsets in patients 3 and $\mathrm{D}$ were also lower than those in the other 

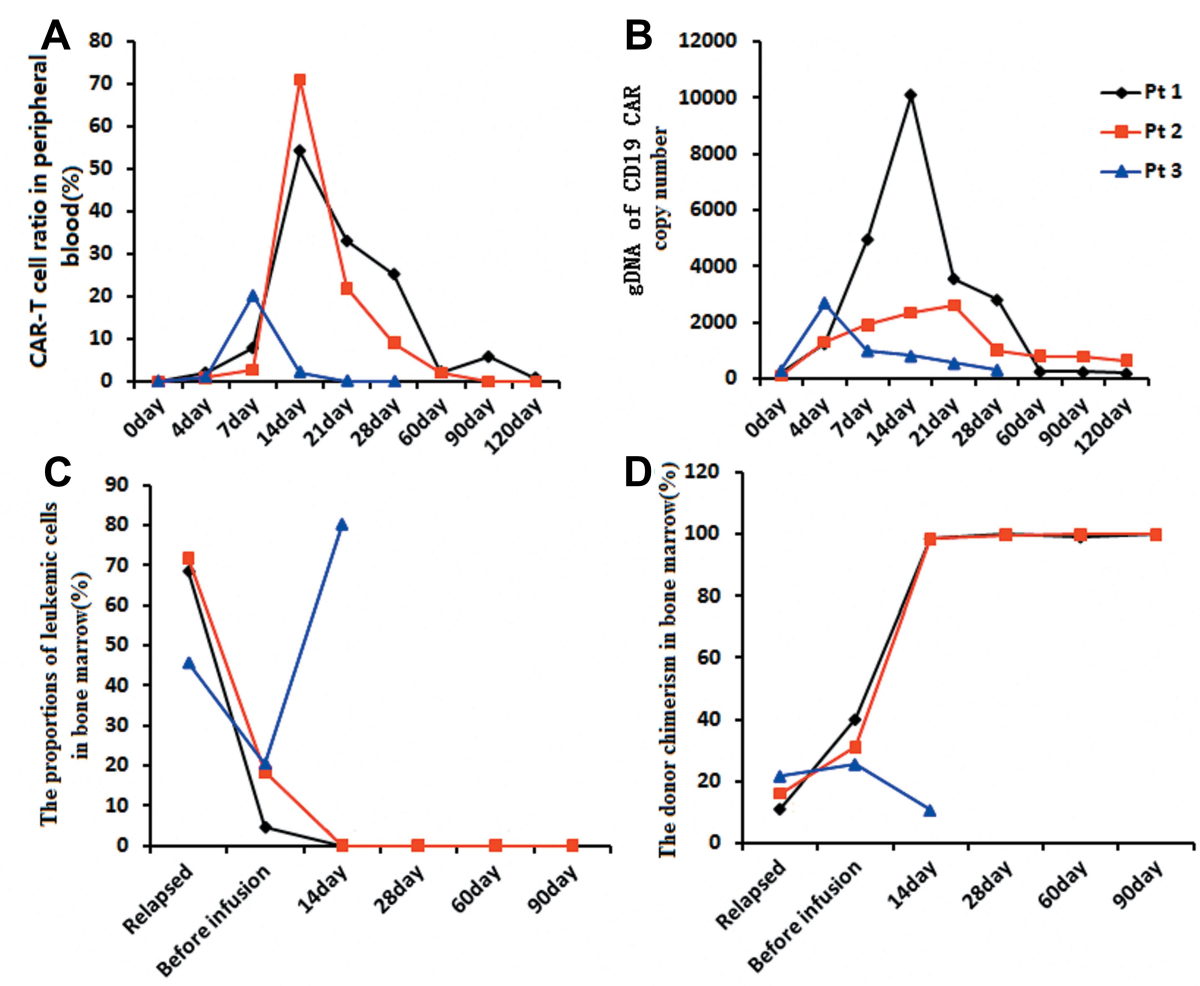

E
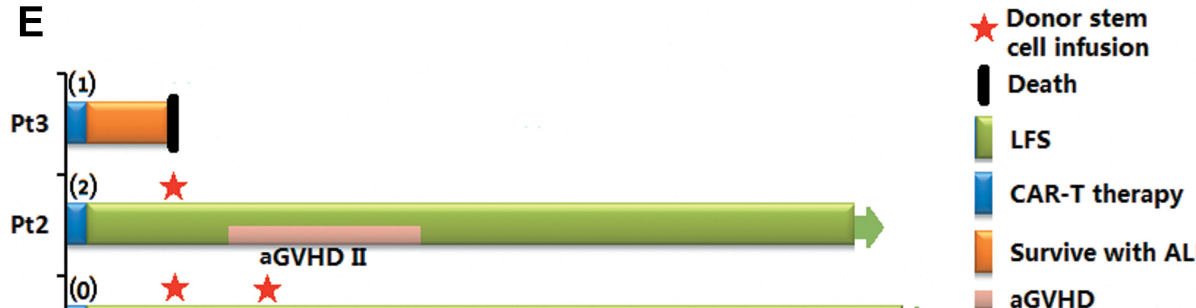

Survive with ALL aGVHD Pt1

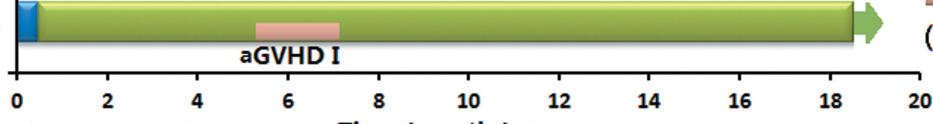

(1)(2)(0) Grade of CRS

Figure 6 CAR-T cell expansion and therapeutic effects in patients I-3. (A) Peak proportion of CAR-T cells using FCM methods. (B) DNA level of the CDI9-CAR gene by qPCR. (C) Leukemic cell proportions using FCM methods. (D) Donor chimerism degrees CAR, chimeric antigen receptor. (E) The CRS, LFS, aGVHD, and death. The peak proportion of CAR-T cells and DNA level of CDI9-CAR gene were higher in patients I and 2 than in patient 3 . The leukemic cells in patients I and 2 disappeared after therapy but increased to $80.2 \%$ in patient 3 . Donor chimerism degrees increased in patients I and 2 .

Abbreviation: CAR, chimeric antigen receptor.

patients whose CAR-T cells or T cells demonstrated strong cytotoxicity towards Nalm 6 cells. Particularly, the CD8 + $\mathrm{T}$ cell absolute numbers were very low. This may potentially underlie the failure of the CD19 CAR-T cell therapy in this case. Additional studies are warranted to confirm this speculation.

Allogeneic CD19 CAR-T cells derived from donors have previously been selected as salvage therapy for B-ALL cases with relapse after allo-HSCT, as allogeneic CD19 CAR-T cells have been found to exert a graft-versus -leukemia effect and diminish the degree of GVHD. ${ }^{24-26}$ Donor-derived CD19 CAR-T cell therapy, which has not been shown to be associated with aGVHD/cGVHD in patients with relapse after allo-HSCT, has resulted in higher remission rates than conventional therapeutic approaches such as DLI. ${ }^{8}$ Donor-derived allogeneic CAR-T cell therapy is highly effective for minimal residual disease without serious side effects, such as GVHD, tumor lysis syndrome, CRS and central nervous system toxicity. $^{21,22}$

However, sometimes, donors cannot provide PBMCs for CD19 CAR-T cell therapy. In our study, we observed the donor chimerism changes and effects of the CD19 CAR-T cells derived from autologous PBMCs obtained 
from the patients with B-ALL with a low level of donor chimerism who relapsed after allo-HSCT. Our study differs from others in that the degree of donor chimerism at the time of PBMC collection was low. ${ }^{27-29}$ In previous studies, the CD19 CAR-T cells were derived from recipients in whom the donor chimerism was not very low. All of these studies have had satisfactory outcomes with recipient-derived CD19 CAR-T cells. Additionally, previous studies did not explain in detail the differences in the donor-origin or recipient-origin CAR-T cells. Previously, there was a concern that receptor-derived CD19 CAR-T cells would not recover donor chimerism due to the low levels of donor chimerism in the receptor. Luckily, however, all the CAR-T cells derived from the patients themselves showed complete restoration of donor chimerism by in vitro culture in this study, although the PBMCs isolated from the patients themselves showed a low level of donor chimerism prior to the culture. Three of the nine patients with B-ALL received CD19 CAR-T cell therapy derived from autologous PBMCs. Patients 1 and 2 achieved CR and complete donor chimerism restoration through the use of this therapy. CD19 CAR-T cell therapy failed in patient 3 , with a low cytotoxicity level of the CAR-T cells to Nalm 6 cells observed in vitro and low CD8 $+\mathrm{T}$ cell absolute numbers.

Patients 1 and 2 exhibited grade 2 CRS without aGVHD during CD19 CAR-T cell therapy. The therapeutic complications in the two patients were similar to those reported in previous studies. However, they presented a very high leukemia load prior to the infusion of CD19 CAR-T cells. Multivariate regression analysis has revealed the risk factors for CRS, which include an elevated marrow tumor burden and high CD19 CAR-T cell infusion dose. ${ }^{30-34}$ In our clinical trial, patients 1 and 2 received a higher pre-treatment dose following the collection of PBMCs. High-dose pre-treatment can reduce the tumor load on the day of CD19 CAR-T cell infusion.

In conclusion, the use of CD19 CAR-T cells derived from patients with recurrence and a low level of donor chimerism after allo-HSCT could lead to complete donor chimerism restoration in vitro, suggesting its potential as a treatment choice for patients whose donors are unable to provide PBMCs.

\section{Data Sharing Statement}

The data used to support the findings of this study are available from the corresponding author upon request.

\section{Ethics Approval and Consent to Participate}

This study was approved by the Medical Ethics Committee of the Tianjin First Central Hospital (Tianjin, China) (Ethics Committee Approval No: 2018N105KY).

This Clinical trial is registered at http://www.chictr.org. cn/index.aspx as ChiCTR1800019622.

The patients agreed to participate in our clinical trials and to the use of their specimens and data for our study.

This trial was conducted in accordance with the Declaration of Helsinki.

\section{Acknowledgments}

We extend our gratitude to the patients for their participation in our experimental studies and clinical trials. We are thankful to the Shanghai Genbase Biotechnology Co., Ltd for providing us with the CD19 CAR-T cells and technical support.

\section{Author Contributions}

Qi Deng contributed to the concept, design and interpretation of data as corresponding author. All authors contributed to acquisition, analysis, and interpretation of data. Qing $\mathrm{Li}$ is the first author. All authors contributed equally to drafting and revising the article and gave final approval of the version to be published, agreed to be accountable for all aspects of the work, and agreed on the journal to which the article will be submitted.

\section{Funding}

There is no funding to report.

\section{Disclosure}

Jijun Yuan and Zhenxing Yang are employees of Shanghai Genbase Biotechnology Co., Ltd. The authors declare that they have no other potential conflicts of interest and that the research was conducted in the absence of any commercial or financial relationships that could be construed as a conflict of interest.

\section{References}

1. Spyridonidis A, Labopin M, Schmid C, et al. Outcomes and prognostic factors of adults with acute lymphoblastic leukemia who relapse after allogeneic hematopoietic cell transplantation. An analysis on behalf of the acute leukemia working party of EBMT. Leukemia. 2012;26 (6):1211-1217. doi:10.1038/leu.2011.351

2. Roddie C, Peggs KS. Donor lymphocyte infusion following allogeneic hematopoietic stem cell transplantation. Expert Opin Biol Ther. 2011;11(4):473-487. doi:10.1517/14712598.2011.554811 
3. Scarisbrick JJ, Dignan FL, Tulpule S, et al. A multicentre UK study of GVHD following DLI: rates of GVHD are high but mortality from GVHD is infrequent. Bone Marrow Transplant. 2015;50(1):62-67. doi:10.1038/bmt.2014.227

4. Park JH, Rivière I, Gonen M, et al. Long-term follow-up of CD19 CAR therapy in acute lymphoblastic leukemia. $N$ Engl $\mathrm{J} \mathrm{Med}$. 2018;378:449-459. doi:10.1056/NEJMoa1709919

5. Lee DW, Kochenderfer JN, Stetler-Stevenson M, et al. T cells expressing CD19 chimeric antigen receptors for acute lymphoblastic leukaemia in children and young adults: a Phase 1 dose-escalation trial. Lancet. 2015;385(9967):517-528. doi:10.1016/S0140-6736(14)61403-3

6. Cruz CR, Micklethwaite KP, Savoldo B, et al. Infusion of donor-derived CD19-redirected virus-specific $\mathrm{T}$ cells for B-cell malignancies relapsed after allogeneic stem cell transplant: a phase 1 study. Blood. 2013;122 (17):2965-2973. doi:10.1182/blood-2013-06-506741

7. Kochenderfer JN, Dudley ME, Carpenter RO, et al. Donor-derived CD19-targeted T cells cause regression of malignancy persisting after allogeneic hematopoietic stem cell transplantation. Blood. 2013;122 (25):4129-4139. doi:10.1182/blood-2013-08-519413

8. Brudno JN, Somerville RP, Shi V, et al. Allogeneic T cells that express an anti-CD19 chimeric antigen receptor induce remissions of B-cell malignancies that progress after allogeneic hematopoietic stem-cell transplantation without causing graft-versus-host disease. $J$ Clin Oncol. 2016;34(10):1112-1121. doi:10.1200/JCO.2015.64.5929

9. Chen Y, Cheng Y, Suo P, et al. Donor-derived CD19-targeted T cell infusion induces minimal residual disease-negative remission in relapsed B-cell acute lymphoblastic leukaemia with no response to donor lymphocyte infusions after haploidentical haematopoietic stem cell transplantation. Br J Haematol. 2017;179(4):598-605. doi:10.11 11/bjh. 14923

10. Jaspers JE, Brentjens RJ. Development of CAR T cells designed to improve antitumor efficacy and safety. Pharmacol Ther. 2017;1 78:83-91. doi:10.1016/j.pharmathera.2017.03.012

11. Pan J, Niu Q, Deng B, et al. CD22 CAR T-cell therapy in refractory or relapsed B acute lymphoblastic leukemia. Leukemia. 2019;33 (12):2854-2866. doi:10.1038/s41375-019-0488-7

12. Lee DW, Gardner R, Porter DL, et al. Current concepts in the diagnosis and management of cytokine release syndrome. Blood. 2014;124(2):188-195. doi:10/1182/blood-2014-05-552729

13. Gökbuget N, Stanze D, Beck J, et al. Outcome of relapsed adult lymphoblastic leukemia depends on response to salvage chemotherapy, prognostic factors, and performance of stem cell transplantation. Blood. 2012;120(10):2032-2041. doi:10.1182/blood-2011-12-399287

14. O’Brien S, Schiller G, Lister J, et al. High-dose vincristine sulfate liposome injection for advanced, relapsed, and refractory adult Philadelphia chromosome-negative acute lymphoblastic leukemia. J Clin Oncol. 2013;31(6):676-683. doi:10.1200/JCO.2012.46.2309

15. Forman SJ, Rowe JM. The myth of the second remission of acute leukemia in the adult. Blood. 2013;121(7):1077-1082. doi:10.1182 blood-2012-08-234492

16. Castagna L, Sarina B, Bramanti S, Perseghin P, Mariotti J, Morabito L. Donor lymphocyte infusion after allogeneic stem cell transplantation. Transfus Apher Sci. 2016;54:345-355. doi:10.1016/j. transci.2016.05.011

17. Rambaldi A, Biagi E, Bonini C, Biondi A, Introna M. Cell-based strategies to manage leukemia relapse: efficacy and feasibility of immunotherapy approaches. Leukemia. 2015;29(1):1-10. doi:10.10 38/leu.2014.189

18. de Lima M, Porter DL, Battiwalla M, et al. Proceedings from the national cancer institute's second international workshop on the biology, prevention, and treatment of relapse after hematopoietic stem cell transplantation: part III. Prevention and treatment of relapse after allogeneic transplantation. Biol Blood Marrow Transplant. 2014; 20:4-13. doi:10.1016/j.bbmt.2013.08.012
19. Collins RH, Shpilberg O, Drobyski WR, et al. Donor leukocyte infusions in 140 patients with relapsed malignancy after allogeneic bone marrow transplantation. J Clin Oncol. 1997;15(2):433-444. doi:10.1200/JCO.1997.15.2.433

20. Kochenderfer JN, Dudley ME, Kassim SH, et al. Chemotherapyrefractory diffuse large B-cell lymphoma and indolent B-cell malignancies can be effectively treated with autologous T cells expressing an anti-CD19 chimeric antigen receptor. J Clin Oncol. 2015;33 (6):540-549. doi:10.1200/JCO.2014.56.2025

21. Liu J, Zhong JF, Zhang X, Zhang C. Allogeneic CD19-CAR-T cell infusion after allogeneic hematopoietic stem cell transplantation in B cell malignancies. J Hematol Oncol. 2017;10(1):35. doi:10.1186/ s13045-017-0405-3

22. Anwer F, Shaukat AA, Zahid U, et al. Donor origin CAR T cells: graft versus malignancy effect without GVHD, a systematic review. Immunotherapy. 2017;9(2):123-130. doi:10.2217/imt-2016-0127

23. Hainz U, Obexer P, Winkler C, et al. Monocyte-mediated T-cell suppression and augmented monocyte tryptophan catabolism after human hematopoietic stem-cell transplantation. Blood. 2005;105 (10):4127-4134. doi:10.1182/blood-2004-05-1726

24. Gill S, Tasian SK, Ruella M, et al. Preclinical targeting of human acute myeloid leukemia and myeloablation using chimeric antigen receptor-modified T cells. Blood. 2014;123(15):2343-2354. doi:10.11 82/blood-2013-09-529537

25. Ghosh A, Smith M, James SE, et al. Donor CD19 CAR T cells exert potent graft-versus-lymphoma activity with diminished graft-versushost activity. Nat Med. 2017;23(2):242-249. doi:10.1038/nm.4258

26. Magnani CF, Biondi A, Biagi E. Donor-derived CD19-targeted $\mathrm{T}$ cells in allogeneic transplants. CurrOpinHematol. 2015;22: 497-502. doi:10.1097/MOH.0000000000000178

27. Liu J, Zhang X, Zhong JF, Zhang C. CAR-T cells and allogeneic hematopoietic stem cell transplantation for relapsed/refractory B-cell acute lymphoblastic leukemia. Immunotherapy. 2017;9(13):111 5-1125. doi:10.2217/imt-2017-0072

28. Hu Y, Wang J, Wei G, et al. A retrospective comparison of allogenic and autologous chimeric antigen receptor $\mathrm{T}$ cell therapy targeting CD19 in patients with relapsed/refractory acute lymphoblastic leukemia. Bone Marrow Transplant. 2019;54(8):1208-1217. doi:10. 1038/s41409-018-0403-2

29. Dai H, Zhang W, Li X, et al. Tolerance and efficacy of autologous or donor-derived $\mathrm{T}$ cells expressing CD19 chimeric antigen receptors in adult B-ALL with extramedullary leukemia. Oncoimmunology. 2015;4(11):e1027469. doi:10.1080/2162402X.2015.1027469

30. Hay KA, Hanafi LA, Li D, et al. Kinetics and biomarkers of severe cytokine release syndrome after CD19 chimeric antigen receptor-modified T-cell therapy. Blood. 2017;130(21):2295-2306. doi:10.1182/blood-2017-06-793141

31. Turtle CJ, Hanafi LA, Berger C, et al. CD19 CAR-T cells of defined CD4+: CD8+composition in adult B cell all patients. J Clin Invest. 2016;126(6):2123-2138. doi:10.1172/JCI85309

32. Turtle CJ, Hanafi LA, Berger C, et al. Immunotherapy of nonHodgkin's lymphoma with a defined ratio of CD8+ and CD4+ CD19specific chimeric antigen receptor-modified T cells. Sci Transl Med. 2016;8(355):355ra116. doi:10.1126/scitranslmed.aaf8621

33. Maude SL, Teachey DT, Porter DL, Grupp SA. CD19-targeted chimeric antigen receptor T-cell therapy for acute lymphoblastic leukemia. Blood. 2015;125(26):4017-4023. doi:10.1182/blood-201 4-12-580068

34. Davila ML, Riviere I, Wang X, et al. Efficacy and toxicity management of $19-28 \mathrm{z}$ CAR $\mathrm{T}$ cell therapy in B cell acute lymphoblastic leukemia. Sci Transl Med. 2014;6(224):224ra25. doi:10.1126/ scitranslmed.3008226 


\section{Publish your work in this journal}

OncoTargets and Therapy is an international, peer-reviewed, open access journal focusing on the pathological basis of all cancers, potential targets for therapy and treatment protocols employed to improve the management of cancer patients. The journal also focuses on the impact of management programs and new therapeutic agents and protocols on patient perspectives such as quality of life, adherence and satisfaction. The manuscript management system is completely online and includes a very quick and fair peer-review system, which is all easy to use. Visit http://www.dovepress.com/ testimonials.php to read real quotes from published authors.

Submit your manuscript here: https://www.dovepress.com/oncotargets-and-therapy-journal 